\title{
How Big Is the Prize Money Gap? Analysis of Prize Money in 2016 Grand Slam Tournaments
}

\author{
Martin Svoboda, Zuzana Rakovská \\ Masaryk University \\ Faculty of Economics and Administration, Department of Finance \\ Lipová 41a, 60200 Brno, Czech Republic \\ E-mail: Martin.Svoboda@econ.muni.cz,zuzana.rak@gmail.com
}

\begin{abstract}
Since 2007 all Grand Slam tournaments have offered equal prize money for male and female tennis players. Although men and women are paid equally in Grand Slams they still play a different number of best-of sets - men play best-of-five set matches while women play best-of-three set matches. Those two competing circumstances created a financial gap in prize money paid to women and men for the unit of effort in a tennis play - for a game. The present paper estimates this financial gap for 2016 Grand Slam tournaments. Moreover, it demonstrates the nominal magnitude of this gap and its effect on year-to-year increasing prize money that are paid to winners. The results showed that women on average obtained $60 \%$ more prize money for a game played than men in all four 2016 Grand Slams.
\end{abstract}

Keywords: tennis, sports finance, gender inequality, gender bias, prize money

JEL codes: G02, Z21, Z23

\section{Introduction}

Tennis is a ball game that can be played by both men and women. Tennis is one of the most popular sports in the world. It is estimated that more than 1 billion people play or watch tennis regularly, mostly in wealthier countries around the world.

The current form of tennis originated in 1874 when the Englishman Walter Clopton Wingfield patented tennis rules (ITHF, 2016). The International Tennis Federation ILTF (International Lawn Tennis Federation) was founded in 1913 and since 1977 has held the name ITF (International Tennis Federation). Tennis was a part of the modern Olympic Games since their inception until 1924 when it was dropped from the program due to disagreements between the ILTF and the International Olympic Committee about amateurs' participation. In 1988 tennis was again included as an Olympic discipline.

Tennis has become fully professionalized and its current direction and further development is determined by the professional association of men (ATP) and women (WTA). The ATP (Association of Tennis Professionals) and the WTA (Women's Tennis Association) are responsible for organizing the global professional tennis tours. ATP and WTA World Tour calendar comprises also the Grand Slam tournaments, but the four Grand Slams, namely, US Open, Australian Open, Wimbledon, and French Open are supervised by the International Tennis Federation (ITF). 
These four Grand Slam tournaments are the biggest competitions in the tennis season and historically, they are also the oldest. Wimbledon (a London suburb) held its first tennis tournament already in July 1877. Another three Grand Slam tournaments are held in New York (Flushing Meadows since 1881), Melbourne, Australia (since 1905), and Paris (Roland Garros since 1925).

All four Grand Slams, Australian Open, French Open, Wimbledon, and US Open offer huge prize money to participating tennis players. Prize money given to winners in men's and women's singles events are the highest out of all other individual sports. The Grand Slam tournaments earn millions of dollars in revenue and tennis players are the best paid individuals in the world. They might obtain millions in prize money as well as through sponsorship deals.

Currently, it is rare in professional sports to offer equal prize money to male and female players. Tennis Grand Slam tournaments represent the leading part of those sports that committed to prize money parity and since 2007 all four Grand Slams have been paying the same money to men and women. The main contributor for this emancipation of female tennis players belongs to Women Tennis Association (WTA).

All four Grand Slam tournaments agreed in 1968-69 to allow professional players to compete with amateurs. This started the so-called Open Era in tennis. US Open became the first Grand Slam to pay the same prize money to male and female players in 1973 and it has kept this commitment since then (ITF, 2016c; US Open, 2016). Australian Open created an equal pay in two temporary periods. The first was in the years 1985-1986 and the second period from 1991 to 1995. Since 2001, Australian Open has distributed prize money equally (ITF, 2016c; AO, 2016). Wimbledon and French Open have chosen another way. In 1991 French Open started to pay only 5\% more prize money to male players compared to female players and equal prize money was announced in 2006 (ITF, 2016c; Roland-Garros, 2016). In the case of Wimbledon, the prize money difference was approximately $10 \%$ starting in 1977. Wimbledon, as the last of Grand Slam tournaments, announced prize money parity in 2007 (ITF, 2016c; Wimbledon, 2016).

The aim of the paper is to deliver a comprehensive analysis of single-tennis player prize money and payment structures of all four 2016 Grand Slam tournaments. We will focus on factual data without assessing gender stereotypes or subjective views.

In the central part of this article, we will build our analysis on the fact that women play $37.5 \%$ fewer sets on average than men in each round of Grand Slam tournaments. This follows from the structure of a tennis match, which is different in women's and men's play ${ }^{4}$. Moreover, we assume the same

\footnotetext{
${ }^{4}$ Typically, a tennis single match is a best-of-three set match. Grand Slam tournaments are characterized by the fact that men in singles play best-of-five set matches, while women played only best-of-three set matches. As a result, rounds in women's singles may end up with two or three sets which gives 2,5 sets on average, whereas rounds in men's singles might end up with three, four of five sets, giving 4 sets on average.
} 
tendency for the number of games played. Since prize money is always positive and it is equalized within all four Grand Slams in the year of our study, it follows directly that women are paid $60 \%$ more on average than men for each game played. We note this tendency as the prize money gap.

Under specified conditions, we will calculate and analyze this gap in prize money paid to men and women for an average game played in a given round in 2016 Grand Slam tournaments. Moreover, we will estimate future prize money for all four Grand Slams and using the calculated financial gap we will study the nominal tendencies of prize money paid to winners for a game played.

We have formulated the following research question: Did women on average earn $60 \%$ more of prize money than men for a game played in all four 2016 Grand Slam tournaments? Based on the nature of our research question we chose data only for the one-year period (2016 Grand Slam tournaments).

The paper is organized as follows. Section 1 offers a review of present literature studying the role of gender in sports. In Section 2 we assess the history of Grand Slam tournaments while emphasizing their development and the evolution of prize money for male and female tennis players. The research question is formulated in Section 3. Section 4 describes data used in the analysis and proposes a methodology to be employed. The central part of the present article is formed by Section 5 and Section 6. In Section 5 we examine the results of our study and in Section 6 we offer a general discussion of the studied phenomenon of a financial gap. Finally, Section 7 delivers conclusions of this article.

\section{Gender in Sports - Literature Review}

This article examines single-player payment structures of four Grand Slam tournaments: US Open, Australian Open, Wimbledon, and French Open. The analysis considers men and women separately, and attempts to calculate prize money per game played in order to compare the financial reward between these two groups. The aim of the study is to deliver a comprehensive analysis of factual numbers without assessing gender stereotypes or subjective views. Nevertheless, the concepts such as gender inequality or gender bias could not be entirely avoided when discussing the outcomes of the comparison of prize money for men and women. As a result, we are providing a short review of literature dealing with gender stereotypes in sports.

In general, there is a big literature gap when considering gender inequality in sports. Studies that examine this topic are mainly from social, psychological, or marketing fields. Majority of those articles deal with gender inequality in proportion of media coverage devoted to men/women (Eastman and Billings, 2000, 2001; Higgs et al., 2003; Billings and Young, 2015). The rest are mainly theoretical papers discussing the issue in general (Trolan, 2013; Chalabaev et al., 2013; Fink, 2015). We failed to find and we are not aware of existence of a single article from the financial or economic field of study which would discuss this issue. Despite this gap, the existing literature is capable of providing at least a starting point for the future research. Eastman and Billings 
(2000) examined sports casting on ESPN and CNN channels and sport reporting in New York Times and USA Today newspapers. Their aim was to compare the proportions of time devoted to men and women in sports broadcasting and to find the pattern of gender stereotyping in media news. The paper represents a pilot study for examining gender inequality in everyday sports broadcasting. The authors analyzed a 5-month period so as to find where the peaks of favoritism towards men and women are (US Open, Wimbledon and French Open were part of this period). Authors measured the time devoted to men and women, and recorded the adjectival descriptors applied to men and women by CNN or ESPN hosts, so to examine how genders are described in media through neutrality/factuality of adjectives used. Strong and consistent preference for men in both printed and electronic media was found. Coverage for women was proved to be approximately $5 \%$ in all four types of media.

A similar analysis was conducted in Billings \& Young (2015). Authors studied more than one hundred hours of sports casting on two channels: ESPN and FOX Sports (the study follows research of Coche (2013)) in order to estimate the difference between the proportions of women/men sports. Regardless of media, women's sports were shown approximately $1 \%$ of the time and, when shown, women's sports stories were approximately $70 \%$ of the length of a men's story.

The above stated articles studied gender inequality in broadcasting in general. A few papers also analyzed the situation in specific sports. Eastman \& Billings (2001) examined college basketball matches and found that women basketball coverage represents only $34 \%$ of overall broadcasting. However, authors suggested that there was no significant difference between the overall proportion of commentary in men's and women's games in relation to the proportions of men and women starter athletes. Higgs et al. (2003) measured clock-time devoted to women in 1996 Olympic Games resulting from the phenomenal success of American women athletes. In order to demonstrate whether televised coverage of women sports increased, they compared the measurements to 1992 Olympic Games. Their findings showed that the coverage for women increased in some team sports such as basketball or volleyball and in other sports analyzed remained unchanged. The study thus suggests the effort on the part of televised media to present women athletes in a stronger manner.

Trolan (2013) argued that gender inequality in media news could not disappear unless media re-examine the portrayal of females. The author suggested that the leading problem was in the way the media present female athletes, which is - bodies that only exist to be observed. Chalabaev et al. (2013) discussed gender stereotypes and roles in sport participation and performance. They argue that gender inequality in sports exists partly because of social beliefs (people believe in the differences).

Finally, Fink (2015) reviewed and summarized the quantitative and qualitative differences in media coverage devoted to men and women and discussed the negative impact of this difference on consumer's perceptions on female 
athletes. The author argues that women are "infantilized" and framed, and that there are different production techniques utilized for women and men sports. Firstly, sport commentators refer to female athletes as girls or young ladies while male athletes are rarely referred to as boys. Secondly, male athletes' success is usually attributed to talent or hard work, whereas female success is often assumed to be a result of a good luck. Last but not least, the actual production techniques (on-screen graphics, camera angles, etc.) used for men and women sports cause that women sports are assumed to be less important and exciting.

\section{Grand Slam Tournaments - Short History}

Grand Slam tournaments - Australian Open, French Open, Wimbledon, and US Open, are the most prestigious individual tennis competitions in the world, which are open to all internationally ranked players. Grand Slams are tightly connected to so called Open Era in tennis. It started in 1968 when three Grand Slam tournaments - French Open, Wimbledon, and US Open agreed to allow professional players to compete with amateurs (Australian Open joined one year later, in 1969). Before Open Era, only amateur players participated in Grand Slams. The Open Era - period from May 1968 to present day, is a very important milestone in tennis history. Since its beginning, tennis as a sport, has developed rapidly from the professional players' point of view and importantly, all tennis players participating in tournaments in the Open Era started to be paid based on their performance in the tournaments and not based on their proficiency. Historical statistics about ranking in tournaments or prize money are usually held only within the Open Era, and tennis titles obtained before the Open Era are less valued than those obtained during it.

The term "Grand Slam" originally represents an event of winning all four tournaments within a single season in one calendar year. There are only three tennis players (one man and two women) who achieved Grand Slam in single draws during the Open Era: Rod Laver (1988), Margaret Court (1970), and Steffi Graf (1988) (ITF, 2015a, b).

Grand Slams, among all tennis professional championships, constitute the highest media attention, prize money and the highest amount of ranking points entering ranking systems ${ }^{5}$. Moreover, Grand Slams are the only championships which are organized for both, men and women (other competitions are conducted either entirely for female or male players). This fact yields an opportunity to compare how men and women are treated in professional tennis competitions and what is the most important, it allows us to conduct an analysis in which we will compare the actual prize money earnt by male and female players.

5 There are two ranking systems, one for men conducted by the Association of Tennis Professionals (ATP), and one for women, conducted by the Women's Tennis Association (WTA). The systems are (ITF 2015a, b) Emirates ATP Ranking, and WTA Ranking System, respectively. Number of points players obtain from Grand Slams is twice as high as the most prestigious championships organized by ATP - ATP World Tour Masters 1000, or by WTA - Premier Mandatory Tournaments (ITF, 2015a, b; 2016a). 
Each individual Grand Slam tournament has its own history which will be shortly offered in the next part of this section. We will focus mainly on basic specifics of each Grand Slam and will discuss the history of prize money development and its differences between genders in more detail.

Australian Open is yearly organized in the last two weeks of January as the first Grand Slam tournament of the given season. It was first held in 1905 as a men-only event called "Australasian Championships". Women started to compete in this tournament in 1922 and in 1924 it reached the status of majors and was renamed "Australian Championships". In 1969, after it joined Open Era, it was renamed Australian Open. This Grand Slam is permanently settled in Melbourne as of 1972 and since 1987 it has been played on hard courts (before this year, it was traditionally played on grass).

Prize money for male and female players awarded in singles draws are distributed equally as of 2001 when Australian Open created a mandate for this equal pay. Before this date, there were two temporary periods in which women were paid the same prize money as men, first in 1985 and 1986, then 1991 to 1995 . In 2016 the total prize money in Australian Open for men's or women's singles reached $\$ 15$ million (ITF, 2016c; AO, 2016).

French Open (Roland Garros) has been organized every year between late May and early June since 1891. Initially, it was held as a men's event open only for French players. In 1897 it opened its doors to women and in 1925 if finally allowed international players to join the competition. French Open is permanently staged in Paris in the Roland Garros stadium as of 1928 and is traditionally played on red clay.

Officially, French Open started to pay equal prize money to men and women in 2006, however starting from 1991 there was only a 5\% gap between male and female prize money. In 2016, the total prize money paid for men's or women's singles player was 24,064 million $€$ (ITF, 2016c; Roland-Garros, 2016).

Wimbledon (The Championships) is the oldest Grand Slam tournament (and the oldest tennis tournament in the world) which was first played in 1877. The Ladies' singles were started in 1884. Each year it is held in Wimbledon, a south-west suburb of London, between late June and early July and it is the only Grand Slam which has kept playing on the original game's surface - grass.

Prize money parity in the case of Wimbledon was announced in 2007, but this Grand Slam paid approximately $90 \%$ of men's award to female players as early as in 1977 (ITF, 2016c; Wimbledon, 2016).

US Open, the last Grand Slams tournament of the season, traditionally begins on the last Monday of August and lasts for two weeks. It was first held in 1881 as the U.S. National Championship, in which only men's singles were organized. Women started to compete in this U.S. National Singles Championship six years later, in 1887. At the turn of the Open Era it was renamed US Open. It is the only Grand Slam which was played every year from its inception. In 1978 it was settled in Flushing Meadows which remained its location till present day. Since 1987, it has been played on the hard court. 
In 1973, US Open became the first Grand Slam to pay the same prize money to male and female players and it has kept this commitment since then (ITF, 2016c; US Open, 2016).

\section{Research Question}

The structure of a tennis match, and hence of all four Grand Slam tournaments, is deliberately designed with an odd number of sets to ensure a winner emerges at the end of the match. Typically, tennis competitors play the best two of three sets to determine a winner. However, in Grand Slam tournaments this holds only for women's singles while men play best three of five sets (ITF, 2016b). In other words, rounds in women's singles may end up with two or three sets which gives 2,5 sets on average, whereas rounds in men's singles might end up with three, four of five sets, giving 4 sets on average $^{6}$. Women thus play $37.5 \%$ fewer sets on average than men in each round of Grand Slam tournaments.

Moreover, we assume the same tendency for the number of games played. There are two supporting arguments. Firstly, the set scoring rules are identical for women's and men's draws in singles of all four Grand Slams. In French Open, Wimbledon, and Australian Open, the "Tie-break Set" method is applied to all sets except the final set (fifth in men's draws and third in women's draws), in which "Advantage Set" method is applied. In US Open, "Tie-break Set" method is employed in all sets of both men's and women's singles". This argument implies that the number of games played in a non-final and final set is on average the same in women's and men's singles simply because there are the same scoring rules applied for both genders. Secondly, the number of games played in each round increases with the number of sets played in each round as each set consists from at least six games (set score 6-0). Taking these two arguments into account, we presume that the amount of games played by women and men is proportional to the number of sets played, and hence, women play $37.5 \%$ fewer games on average than men in each round of Grand Slam tournaments.

In 2016 we observed the identical payment structure for female and male players in each of the 2016 Grand Slam tournaments. This means that women at each level of the prize money structure (from the first level in which 64 losers from the first round were paid equal prize money, to the last level in which the winner of the seventh round earns the winner prize money) obtained the same money as men did. Suppose that a male player who was beaten in

\footnotetext{
${ }^{6}$ We are assuming that all two (in women's singles) or three (in men's singles) possible amounts of sets played in a round occur with equal probabilities.

7 There are two main methods of scoring in the tennis sets: the "Advantage Set" and the "Tie-break Set". In "Advantage Set", the first player to win six games wins that "Set", provided there is a margin of two games over the opponent. If necessary, the set shall continue until this margin is achieved. In the "Tie-break Set", the first player to win six games wins that "Set", provided there is a margin of two games over the opponent. If the score is tight at six games all (6-6), a tie-break game is played (Grand Slam Board, 2016).
} 
the third round obtained $x_{3 r d R o u n}$ EUR Prize Money, then also a woman who ended in the third round obtained $x_{3 \text { rdRound }}$ EUR Prize Money.

We concluded in the previous discussion that women play $37.5 \%$ fewer games than men in each of the seven Grand Slam rounds. This implies unequal average prices of a game played by men and women in each tennis round. In other words, if men played in a given round, let us say $3^{\text {rd }}$ round of French Open, on average a hundred games, then women played on average 62.5 games ( $37.5 \%$ fewer). Now, the average prize money for one game played by men in this round is $x_{3 r d R o u n d} / 100$ EUR, while the average prize money for one game played by women in the same round is $x_{3 \text { rdRound }} / 62,5$ EUR. Since prize money is always positive, it follows directly that women are paid $60 \%$ more on average than men for each game played. We note this tendency as the prize money gap. Such trend informs our research question:

Research Question: Women will earn $60 \%$ more on average than men for a game played in all four 2016 Grand Slam tournaments.

\section{Data and Methodology}

Grand Slams are the only professional championships organized for both male and female tennis players. Each Grand Slam is constituted of men's singles, women's singles, men's doubles, women's doubles and mixed doubles tournaments. Prize money for the first two and the second two tournaments are equally distributed in each Grand Slam as of 2007 when Australian Open as the last championship announced prize money parity for both genders. Hence, since 2007, women and men have obtained the same amount of money in all four Grand Slam tournaments.

The goal of this article is to analyze the gap in prize money paid to men and women for an average game played in a given round, resulting from two competing circumstances. On the one hand, women earn the same prize money as men in all four Grand Slams as of 2007. On the other hand, women play fewer best-of sets compared to men - women play best-of-three sets while men play best-of-five sets. In other words, we will examine the gender disparity caused by two types of directly observed functional conditions in tennis play, those that are completely equal, and those that are inexplicably unequal. Equality could be immediately observed in the prize money per player at each level of the payment structure, or the number of competitors in women and men play $(=128)$ which results in the same amount of tournament rounds. Different-across-genders condition might be observed in the amount of best-of sets played.

In order to conduct our study, we decided to examine prize money paid within men's and women's singles of all four Grand Slams - French Open, Australian Open, Wimbledon, and US Open in 2016. The data on prize money and scores in each tournament were obtained from the official web pages of each individual Grand Slam. List of the web pages can be found in the Reference section at the end of this article. 
Table 1 shows the structure of prize money in individual tournaments in $€$. Each Grand Slam is originally denominated in its home currency - Australian Open in Australian \$, French Open in $€$, Wimbledon in $€$, and US Open in \$. Transformation into only one currency was needed to make the numbers comparable. We chose $€$ as the common denominator and used daily exchange rates issued by European Central Bank (ECB) in calculations. Exchange rates used were those that were issued by ECB on the last day of the given championship. The dates for each tournament in 2016 are the following:

- Australian Open: 18-31 January 2016,

- French Open: 22 May-5 June 2016,

- Wimbledon: 27 June-10 July 2016,

- US Open: 29 August-11 September 2016.

Table 1 Grand Slam Prize Money in 2016 [in €]

\begin{tabular}{|c|c|c|c|c|c|}
\hline $\begin{array}{c}\text { Men's/ } \\
\text { Women's } \\
\text { Singles } \\
\end{array}$ & $\begin{array}{c}\# \\
\text { players } \\
\text { paid } \\
\end{array}$ & $\begin{array}{c}\text { Australian } \\
\text { Open } \\
\text { [in C] } \\
\end{array}$ & $\begin{array}{c}\text { French } \\
\text { Open } \\
\text { [in C] }\end{array}$ & $\begin{array}{l}\text { Wimbledon } \\
\text { [in C] }\end{array}$ & $\begin{array}{l}\text { US Open } \\
\text { [in C] }\end{array}$ \\
\hline Winner & 1 & 2501950 & 2000000 & 2346234 & 3106141 \\
\hline Runner-Up & 1 & 1234728 & 1000000 & 1173117 & 1553071 \\
\hline Semifinalists & 2 & 519886 & 500000 & 586558 & 776535 \\
\hline Quarterfinalists & 4 & 259943 & 294000 & 293279 & 399361 \\
\hline Round of 16 & 8 & 129971 & 173000 & 154851 & 208555 \\
\hline Round of 32 & 16 & 63361 & 102000 & 93849 & 124246 \\
\hline Round of 64 & 32 & 38991 & 60000 & 58656 & 68502 \\
\hline Round of 128 & 64 & 22420 & 30000 & 35194 & 38439 \\
\hline Total & 128 & 10552378 & 12032000 & 12735357 & 16118253 \\
\hline
\end{tabular}

Source: The official web pages of Grand Slam tournaments

As discussed above, the goal of this article is to study prize money paid for an average game played at each level of the payment structure. Hence, we needed to collects the second ingredient data - the average amount of games played. To do it, we processed eight scoring tables (four Grand Slams for women's singles and four Grand Slams for men's singles) and for each of them we calculated the amount of games played by all 128 players. In the case of men's draw in 2016 US Open, we needed to perform modification of amount of games played by tennis player Novak Djokovic. Firstly, this modification resulted from the fact that Djokovic had advanced to the third round of the 2016 US Open by walkover because his scheduled opponent had withdrawn due to health conditions. Secondly, Djokovic played only one set in third round and free-passed to the next round again due to his opponent's injuries (US Open, 2016). Since Djokovic ended up in a runner-up position with only 167 games played, we decided to replace it with the average composed of games played by the winner and two semifinalists. The resulting number of games for Djokovic was 227. No other modifications were implemented.

We define the average number of games played at the $i$ th level of the payment structure of the given Grand Slam (GS) as follows: 
AVGgames $_{i g}^{G S}=\frac{\sum_{j=1}^{N_{i}} \operatorname{games}_{j i g}^{G S}}{N_{i}}$

where $g$ represents gender, $N_{i}$ represents the number of players at the $i$ th level of payment structure, $j$ stands for the individual player at the given level of payment structure. Note that there are 8 levels of payment structure in each Grand Slam tournament (see the first column in Table 1) and there are the same amounts of players at each of those levels across Grand Slams and genders (see the second column in Table 1) - ranging from one player at the first and the second level, winner and runner-up, respectively, to 64 players at the eighth level which also represents the first round of the tournament. Moreover, $\sum_{i=1}^{8} N_{i}=128$ for each GS and $g$. Hence, we omitted subscript GS and $\mathrm{g}$ in $N_{i}$ variable.

Further, we define prize money earnt for an average game played at the ith level of payment structure of the given Grand Slam (GS) as follows:

$$
\text { AVGgamePrize }_{i g}^{G S}=\frac{\text { AVGgames }_{i g}^{G S}}{\sum_{j=1}^{N_{i}} \operatorname{Pr} \text { izeMoney }_{j i}^{G S}}
$$

where PrizeMoney ${ }_{j i}^{G S}$ stands for prize money paid to the $j$ th player at the $i$ th level of payment structure of the given Grand Slam (GS).

Finally, we define the financial gap in prize money - how much more prize poney per game women earn compared to men in percent, as follows:

$$
\operatorname{gap}_{i}^{G S}=\frac{\text { AVGgame } \operatorname{Pr} \text { ize } e_{i \text {,Women }}^{G S}-\text { AVGgame } \operatorname{Pr} i z e_{i, \text { Men }}^{G S}}{A V \text { Ggame } \operatorname{Pr} i z e_{i, \text { Men }}^{G S}} * 100 \%
$$

Variables defined in (1), (2) and (3) will be used in our analysis. Based on the nature of our research question and the fact that we are employing data only for one-year period (2016 Grand Slam tournaments), the methodology for our study is limited to basic statistical and visual representation of the data, while more complex analysis is not feasible. Nevertheless, we will provide a comprehensive examination of the studied phenomena and will deliver results that will function as a starting point for further study. As outlined, we will proceed in the examination of our research question as follows. First, we will quantify the average prize money for each level of the payment structure in all four Grand Slams for both, men and women. Second, using the nominal gender gap (the difference) in payments of tennis players we will be able to calculate and visualize how much were women paid for an average game played in Grand Slams. This result would then serve as an answer for the research question formulated in Section 2. 


\section{Results}

Using scoring tables and formula (1) we calculated AVGgames $s_{i g}^{G S}$ for each level $i$ of payment structure defined for either Australian Open, French Open, Wimbledon, or US Open, paid to men and then women.

Figure 1 Average amount of games at each prize money level - Women and men comparison

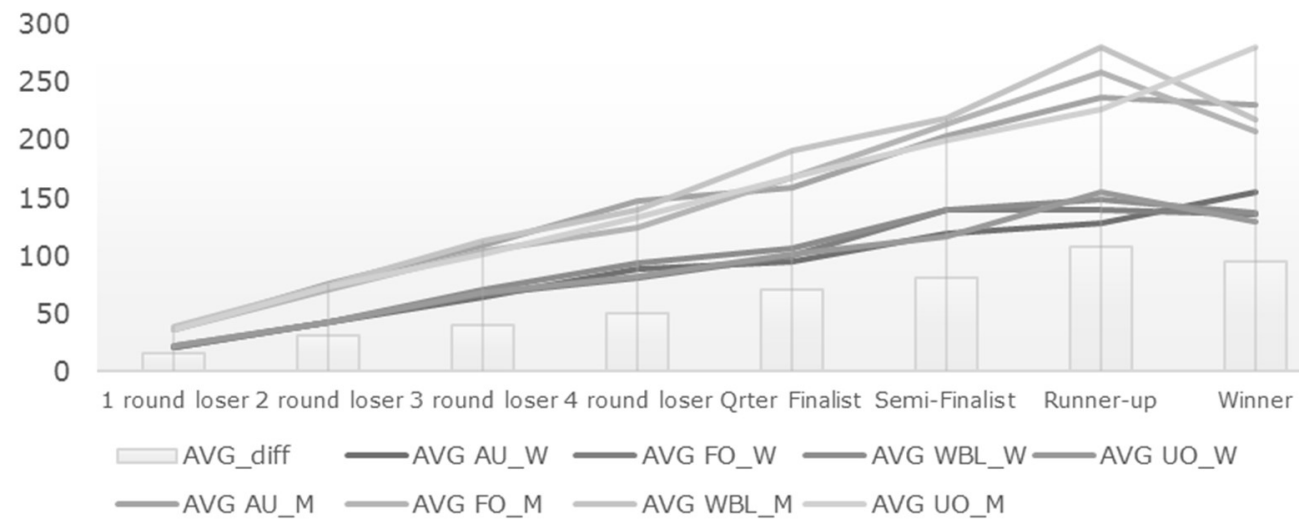

Source: Authors' own calculations, the official web pages of Grand Slam tournaments

Figure 1 plots the values. The upper four lines represent the average number of games played by male tennis players and the lower four lines represent the female values. Column bars placed below the lines show the differences between the amount of games played by men and women at each level of payment structure averaged across four Grand Slams.

This figure clearly confirms our assumption from Section 3 - women play fewer games than men in each round of Grand Slam tournaments. As the next step, we also wanted to check whether the extent of this difference is proportional to the number of sets played. We have calculated the average number of sets and games played at each level of payment structure across Grand Slams for men and women and then we expressed the differences between male and female players in terms of men's values. Figure 2 summarizes our observations and shows that our assumption from Section 3 was almost correct - women play $40 \%$ fewer games on average than men in each round of Grand Slam tournaments based on the data from 2016 championships.

The core part of our study is to calculate the financial gap in average prize money paid for a game played by men and women at each level of payment structure of four Grand Slam tournaments. Using formula (1) we calculated the average number of games at each level. Employing these numbers in formula (2) and inserting prize money values from Table 1 we arrived to the desired values representing the prize money earnt for an average game played at each level of payment structure of every Grand Slam. Using formula (3) we then calculated the financial gaps. Table 2 brings the summary. 
Figure 2 Average number of games versus sets - proportional representation

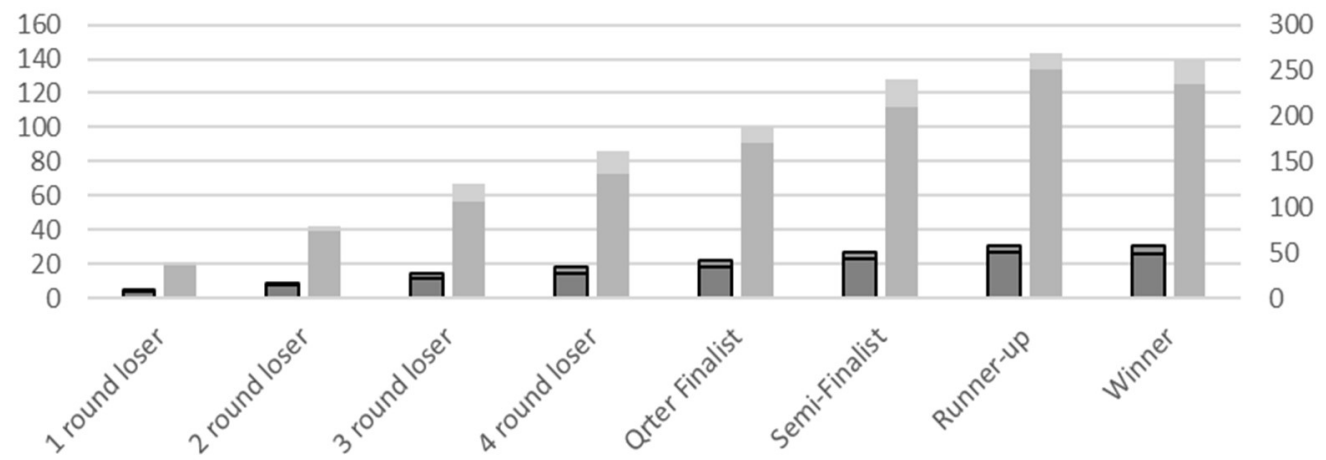

口AVGgames Men $\square$ AVGgames Women $\quad$ AVGsets Men $\square$ AVGsets Women

Source: Authors' own calculations, the official web pages of Grand Slam tournaments

As shown in Table 2, women were paid more for each game played compared to men in all 2016 Grand Slam tournaments. This gap represented in all four championships more than $60 \%$ on average in lines with our prediction. The highest difference can be seen in case of prize money paid to runner-up tennis players in Wimbledon - prize money obtained for each game played by Angelique Kerber was $7873 €$ while the respective game prize money obtained by male runner-up Milos Raonic was $4190 €$. Generally, the highest differences in game prize money representing more than $80 \%$ are visible in runner-up level of payment structures of all four Grand Slams (the same pattern is visible in Figure 1 and Figure 2). Since we are processing the data only for one season, we will not raise any conclusions based on variances in magnitudes across levels. Nevertheless, the predicted pattern of $60 \%$ gap in prize money in men's versus women's singles was showed to hold in all 2016 Grand Slams.

Table 2 Average financial gap in prize money per game - How much more women earn for a game

\begin{tabular}{lcccc}
\hline $\begin{array}{c}\text { Men's/Women's } \\
\text { Singles }\end{array}$ & $\begin{array}{c}\text { Australian } \\
\text { Open }\end{array}$ & French Open & Wimbledon & US Open \\
\hline \hline Winner & $48 \%$ & $53 \%$ & $59 \%$ & $76 \%$ \\
\hline Runner-up & $85 \%$ & $85 \%$ & $88 \%$ & $81 \%$ \\
\hline Semifinalist & $72 \%$ & $54 \%$ & $58 \%$ & $72 \%$ \\
\hline Quarterfinalist & $68 \%$ & $66 \%$ & $81 \%$ & $65 \%$ \\
\hline Round of 16 & $66 \%$ & $54 \%$ & $49 \%$ & $62 \%$ \\
\hline Round of 32 & $70 \%$ & $57 \%$ & $61 \%$ & $48 \%$ \\
\hline Round of 64 & $78 \%$ & $67 \%$ & $76 \%$ & $74 \%$ \\
\hline Round of 128 & $72 \%$ & $72 \%$ & $79 \%$ & $70 \%$ \\
\hline $\begin{array}{l}\text { Average per } \\
\text { Grand Slam }\end{array}$ & $\mathbf{7 0 \%}$ & $\mathbf{6 3 \%}$ & $\mathbf{6 9 \%}$ & $\mathbf{6 9 \%}$ \\
\hline
\end{tabular}

Source: Authors' own calculations, the official web pages of Grand Slam tournaments 


\section{Discussion}

In the previous section we showed that there is a financial gap in prize money paid for a game played by men and women in all four 2016 Grand Slam tournaments. The amount of this financial gap is significant and reached $60 \%$ on average, systematically in all four championships - Australian Open, French Open, Wimbledon, and US Open. In other words, women earnt $60 \%$ more money on average than men for the same effort exerted in a game.

This gap which favors women in prize money obtained could be considered extremely controversial in the current world still exhibiting the tendency of men earning more money in a wide spectrum of activities. This gender inequality has its roots in beliefs about sex differences, such as physical strength or ability to cope with stressful situations. In popular and medialized sports, it is common to observe an opposite direction of prize money gap than the one identified in Grand Slam tournaments. This is mostly visible in team sports such as football or basketball, but also in individual sports such as golf. Valian (1999) argues that this serious problem which systematically places women to worse positions than men not only in a matter of salary, but also in a matter of professional status is caused by stereotyping and gender schemas that cannot be changed or removed over the short run ${ }^{8}$.

The fact that all four Grand Slams offer the equal prize money for both genders while women demonstrably play fewer best-of sets might seem unfair and intriguing. The other view, however, is that the International Tennis Federation together with individual Grand Slam national organizations exert effort to flatten the present gender inequality in sports and that equal payment structure for male and female tennis players might stand as the pioneering example for future development of women's position in sports. Continuing in this debate is not the aim of our article; however, we feel that it is important to summarize the views of this phenomenon in media. We stress out that our intent is to discuss the calculated financial gap that is currently present in the payment structure of Grand Slam tournaments objectively and without taking any sides in judgement.

There are two possible scenarios that are extensively discussed in media and that react to the fact that Grand Slams offer the same prize money to men and women while the number of best-of sets played by both genders remains unequal: (1) Women and men should both play best-of-5 sets in Grand Slams and everyone would get equal prize money, (2) Number of best-of sets should remain unchanged (men play best-of-five sets and women play best-of-three sets in Grand Slams) and men should get proportionally more prize money. We will not discuss option (2) as it suggests bringing the tennis world a few decades back in history and does not offer a solution which would cope with gender inequality in sports. Option (1) is thus more frequently proposed

8 Trolan (2013) discussed the gender stereotyping in tennis and suggested that athletic achievements of women are devalued by the language used by commentators. This language often exhibits the pattern of trivialization when women are called "babes" or "girls" and propose the idea that men are the dominant gender. 
solution and there are two competing camps proposing arguments for and against its feasibility. The first camp arguing against the amount-of-best-ofsets equalization suggests physical constraints of women according to which women are not capable of playing five sets. The next argument they discuss is that women's play is usually longer than men's play which in five sets setting might cause extremely long matches and this might affect media coverage. The counterarguments are built on observations from other sports, such as biathlon, in which women are capable of the same performance as men and they suggest that this should hold for all sports. Other arguments are based on claim that women train the same amount of time as men and hence should be presented with the equal opportunities.

The following subsection examines the extent of the studied financial gap in nominal terms and attempts to provide nominal value of this gap in future periods.

\subsection{Development of the Financial Gap in Future Periods}

The goal of this section is to comment on the future development of prize money in Grand Slam tournaments and to attempt to provide an estimate of prize money paid to male and female winners per game played in future Grand Slams. By this, we want to demonstrate the nominal magnitude of the gap calculated in section 5 and its effect on yearly increasing prize money paid to winners. As outlined, in this section we will concentrate only on the financial gaps present at the first level of payment structure - prize money paid to winners of Grand Slams. The reason why we are limiting our discussion only to one level of prize money is the limited availability of historical data for overall decompositions of payment structure and overall prize money for men's or women's singles as a whole. Data on prize money paid to winners could be found at official web pages of each individual Grand Slam - Australian Open, French Open, Wimbledon, and US Open - or in historical articles commenting on each-year Grand Slam titles.

The overall gap in each of 2016 Grand Slams was calculated to be more than $60 \%$ (Table 2). In the case of the winner level of payment structure we observe variation among championships ranging from $48 \%$ (Australian Open) to $76 \%$ (US Open). Based on the definition of formulas (1) and (2), individual gaps calculated through formula (3) only depends on the average amount of games played by men or women at the given level of payment structure. This follows from the fact that prize money for each level are equal for both genders. Furthermore, as we showed in section 5, the amount of games played depends on the amount of sets in the play. Assuming that the rules customizing the number of sets played in all Grand Slams remain the same in next periods (women are playing best-of-three sets while men play best-offive sets), we can expect only a small variation in the number of games played at each level of payment structure throughout tennis seasons. As a result, we expect that there would be only a small variation in the average number of games played by winners in future Grand Slam tournaments, if any. Therefore, without a loss of generality, we will take an average of the number of games played by male and female winners, and also of gaps in prize money paid to 
winners which we calculated for each 2016 Grand Slam, and will assume the average numbers for winners as a constant entering future Grand Slam seasons. Table 4 provides a summary.

Table 4 Average amount of games played by men and women - Winners in Grand Slams

\begin{tabular}{lccccc}
\hline & $\begin{array}{c}\text { Australian } \\
\text { Open }\end{array}$ & $\begin{array}{c}\text { French } \\
\text { Open }\end{array}$ & Wimbledon & $\begin{array}{c}\text { US } \\
\text { Open }\end{array}$ & Average \\
\hline \hline \# games Women & 155 & 136 & 137 & 129 & $\mathbf{1 3 9}$ \\
\hline \# games Men & 230 & 208 & 218 & 281 & $\mathbf{2 3 4}$ \\
\hline Gap & $48 \%$ & $53 \%$ & $59 \%$ & $76 \%$ & $\mathbf{5 9 \%}$ \\
\hline
\end{tabular}

Source: Authors' own calculations, the official web pages of Grand Slam tournaments

As the next step, we estimated the future development of prize money paid to winners 4 years ahead - till 2020. To obtain these values we used historical data on winner prize money and by employing the exponential trend line, we forecasted future prize money for winners ${ }^{9}$. For each Grand Slam we only utilized the data from periods of prize money parity. The rationale for this is offered by our study design in which we are analyzing the gap resulting from two competing circumstances - women earn the same prize money as men in all four Grand Slams while at the same time, women play fewer best-of sets compared to men. Hence, it would be of no value to study periods in which prize money for winners was not equal across genders. The milestones for prize money parity were identified in section 2 as follows:

- Australian Open - from 2001,

- French Open - from 2006,

- Wimbledon - from 2007,

- US Open - from 1973.

Figure 3 shows the development of prize money for winners in home currency, that is Australian Open in Australian \$, French Open in $€$, Wimbledon in $£$, and US Open in $\$$. The solid thick line displays historical data ranging from the year in which individual Grand Slams announced prize money equality till 2016. The solid thin line represents exponential trend till 2020.

Based on the estimated values for future prize money for winners and by employing the average values from Table 4, we were able to calculate prize money paid for a game played by male and female winners in 2020. Table 5 presents the values in comparison to real 2016 Prize Money.

\footnotetext{
9 We employed the exponential trend because it best fitted the historical data compared to the linear or quadratic trend. The assessment was made based on values of $\mathrm{R}^{2}$.
} 
Figure 3 Winner Prize Money trend in Grand Slams - True development and exponential trend

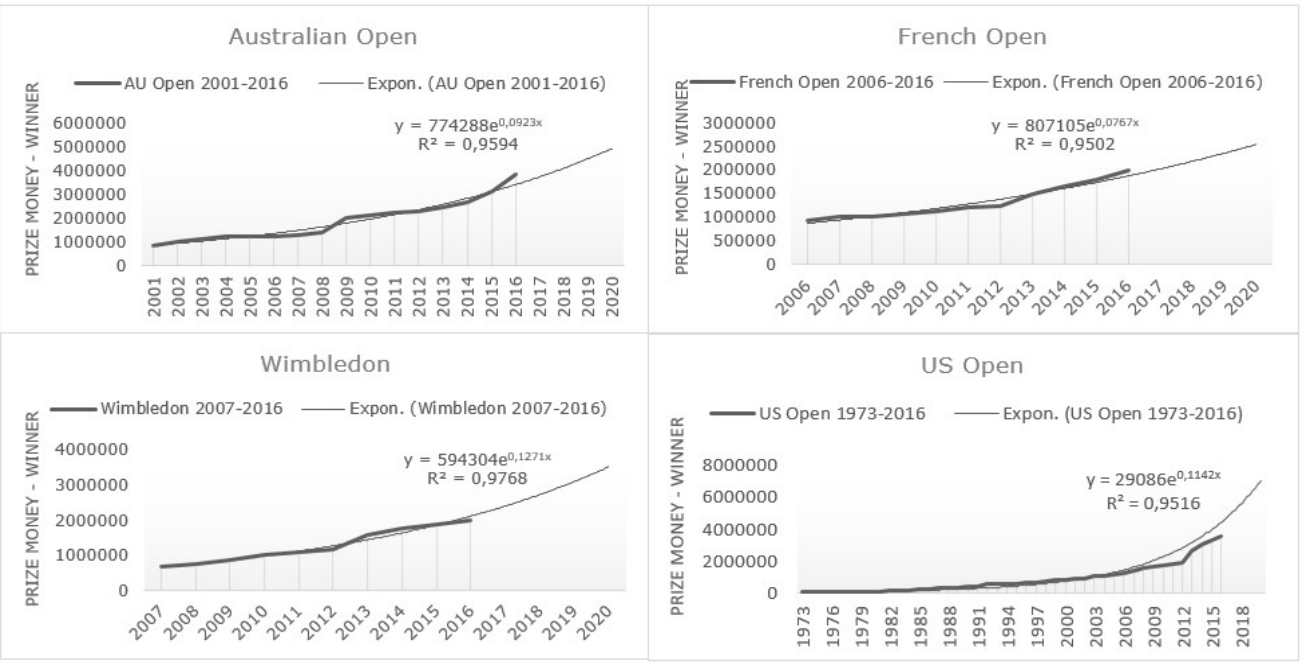

Source: Authors' own calculations, the official web pages of Grand Slam tournaments

It can be seen that the highest increase in winner prize money was estimated for US Open which also created the widest nominal gap in prize money paid for a game among four Grand Slams - in 2020, women are estimated to obtain approximately $\$ 20000$ more prize money for one game played compared to men.

Table 5 Prize Money paid to winners in 2016 and 2020 Grand Slam - overall and for a game played

\begin{tabular}{lcccc}
\hline $\begin{array}{c}\text { Prize Money for } \\
\text { Winners in Year }\end{array}$ & $\begin{array}{c}\text { Australian } \\
\text { Open }[\mathbf{\$}]\end{array}$ & $\begin{array}{c}\text { French } \\
\text { Open }[\boldsymbol{C}]\end{array}$ & $\begin{array}{c}\text { Wimbledon } \\
{[\boldsymbol{E}]}\end{array}$ & $\begin{array}{c}\text { US Open } \\
{[\$]}\end{array}$ \\
\hline \hline 2016 - real & 3850000 & 2000000 & 2000000 & 3500000 \\
\hline Game Prize - women & $\mathbf{2 4 8 3 9}$ & $\mathbf{1 4 7 0 6}$ & $\mathbf{1 4 5 9 9}$ & $\mathbf{2 7 1 3 2}$ \\
\hline Game Prize - men & $\mathbf{1 6 7 3 9}$ & $\mathbf{9 6 1 5}$ & $\mathbf{9 1 7 4}$ & $\mathbf{1 2 ~ 4 5 6}$ \\
\hline 2020 - estimate & 4907985 & 2548806 & 3522984 & 6971010 \\
\hline Game Prize - women & $\mathbf{3 5 2 4 6}$ & $\mathbf{1 8 3 0 4}$ & $\mathbf{2 5 3 0 0}$ & $\mathbf{5 0 0 6 1}$ \\
\hline Game Prize - men & $\mathbf{2 0 ~ 9 5 2}$ & $\mathbf{1 0 ~ 8 8 1}$ & $\mathbf{1 5 0 3 9}$ & $\mathbf{2 9 7 5 9}$ \\
\hline
\end{tabular}

Source: Authors' own calculations, the official web pages of Grand Slam tournaments

\section{Conclusions}

This article examined prize money of four Grand Slam tournaments: US Open, Australian Open, Wimbledon, and French Open in 2016. All of these tournaments pay equal prize money to male and female tennis players as of 2007 when Australian Open as the last championship announced prize money parity. Although men and women are paid equally they still play a different number of best-of sets in Grand Slams - men play best-of-five sets while women playing best-of-three sets. These two competing circumstances have 
given rise to a financial gap in prize money obtained for a game played by men compared to women. The present paper estimated this financial gap for 2016 Grand Slam tournaments.

The results of the analysis showed that women earn $60 \%$ more prize money for a game played on average. This difference in salaries was systematically presented in all four Grand Slam tournaments. Gaps were also calculated for each level of payment structure ranging from winner prize money to prize money paid to 64 losers from the first round of the championships. The gaps varied across individual levels from $48 \%$ to $88 \%$.

We also demonstrated the nominal magnitude of the gap computed for 2016 Grand Slams and its effect on year-to-year increasing prize money that are paid to winners. We estimated future prize money for winners using exponential trend lines and employing 2016 gap we calculated prize money paid for a game played by winning women or men. Results showed the widest financial gap in nominal terms in the case of US Open championship. We estimated that in 2020, a female winner will be earning $\$ 50061$ for a game played while a male winner would obtain only $\$ 29759$ for the same effort in play.

The outputs that favor women in prize money obtained could be considered extremely controversial in the current world still exhibiting the tendency of men earning more money in a wide spectrum of activities. The aim of this paper was hence to approach the gap quantitatively and deliver a comprehensive analysis of factual numbers without assessing any subjective judgments or beliefs about sex differences.

Finally, this article represents a pilot study of the phenomena of prize money in Grand Slams. We are not aware of any other paper which would discuss the financial gap in prize money obtained by a game played by men and women. The topic is very wide and covers several fields from sociology to behavioral finance. We can raise several recommendations for future research. Firstly, we employed data from 2016 Grand Slams only. The future research should concentrate on more Grand Slam seasons. Secondly, the data were processed with the use of basic statistical methods and the main part of the methodology was based on graphical visualization of the data. For the future research we recommend more complex statistical methods. Eventually, the study could be extended to other professional tennis tournaments organized by the Association of Tennis Professionals (ATP), and the Women's Tennis Association (WTA).

\section{Acknowledgments}

Support of Masaryk University within the project MUNI/A/0916/2015 "Behavioral and knowledge aspects of trading and pricing financial assets" is gratefully acknowledged. 


\section{References}

AO (2016). Available at: http://event.ausopen.com, (accessed 10.11.2016).

Billings, A. and Young, D. B. (2015). Comparing Flagship News Programs: Women's Sport Coverage in ESPN's SportsCenter and FOX Sports 1's FOX Sports Live. Electronic News, 9(1), pp. 3-16.

Chalabaev, A., Sarrazin, P., Fontayne, P., Boiche, J. and Clement-Guillotin, C. (2013). The Influence of Sex Stereotypes and Gender Roles on Participation and Performance in Sport and Exercise: Review and Future Directions. Psychology of Sport and Exercise, 14(2), pp. 136-144.

Coche, R. (2013). Is ESPN Really the Women's Sports Network? A Content Analysis of ESPN's Internet Coverage of the Australian Open. Electronic News, 7(2), pp. 72-88.

Eastman, S. T. and Billings, A. C. (2000). Sportscasting and Sports Reporting. Journal of Sport \& Social Issues, 24(2), pp. 192-213.

Eastman, S. T. and Billings, A. C. (2001). Biased Voices of Sports: Racial and Gender Stereotyping in College Basketball Announcing. Howard Journal of Communications, 12(4), pp. 183-201.

Fink, J. S. (2015). Female Athletes, Women's Sport, and the Sport Media Commercial Complex: Have We Really "come a long way, baby"? Sport Management Review, 18(3). pp. 331-342.

Grand Slam Board (2016). 2016 Official Grand Slam Rule Book. Available at: http://www.itftennis.com/media/220770/220770.pdf, (accessed 3.11.2016).

Higgs, C. T., Weiller, K. H. and Martin, S. B. (2003). Gender Bias in the 1996 Olympic Games. Journal of Sport \& Social Issues, 27(1), pp. 52-64.

ITF (2015a). Emirates ATP Ranking. Available at: http://www.itftennis.com/media/221169/221169.pdf, (accessed 3.11.2016).

ITF (2015). WTA Ranking System. Available at: http://www.itftennis.com/media/221170/221170.pdf, (accessed 3.11.2016).

ITF (2016a). ITF Constitution. Available at: http://www.itftennis.com/about/ organisation/constitution.aspx, (accessed 3.11.2016).

ITF (2016b). ITF Rules of Tennis 2016. Available at: http://www.itftennis.com/media/220771/220771.pdf, (accessed 3.11.2016).

ITF (2016c). Available at: http://www.itftennis.com, (accessed 10.11.2016).

ITHF (2016). Patent for Tennis. International Tennis Hall of Fame. Available at: https://www.tennisfame.com/blog/2016/1/a-patent-for-tennis/, (accessed 10.11.2016).

Roland-Garros (2016). Available at: http://www.rolandgarros.com/en_FR/ index.html, (accessed 10.11.2016).

Trolan, E. J. (2013). The Impact of the Media on Gender Inequality within Sport. Procedia - Social and Behavioral Sciences, 91, pp. 215-227.

US Open (2016). Available at: http://www.usopen.org/index.html, (accessed 10.11.2016).

Valian, V. (1999). The Cognitive Bases of Gender Bias. Brooklyn Law Review, 65(4), pp. 1037-1061.

Wimbledon (2016). Available at: http://www.wimbledon.com, (accessed 10.11.2016). 